\title{
Fabrication of Multilayer Graphene by an Environment-friendly Synthesis of Metallic Magnesium and Carbon Dioxide Combined in a Chemical Reaction
}

\author{
E. Cuadros-Lugo ${ }^{1}$, D. Lardizabal-Gutiérrez ${ }^{1}$, J.M. Herrera-Ramirez ${ }^{1}$, C. Garay-Reyes ${ }^{1}$, C. López- \\ Meléndez ${ }^{2}$ and C. Carreño-Gallardo ${ }^{1}$ \\ 1. Centro de Investigación en Materiales Avanzados (CIMAV). Laboratorio Nacional de \\ Nanotecnología. Chihuahua, Chih., México. \\ 2. Universidad La Salle Chihuahua, Prol. Chihuahua, México.
}

Graphene oxide (GO) and reduced graphene oxide (RGO) has been studied recently in fields like electronics, energy storage, biomedical applications, biosensors and as a reinforcement for metallic and polymeric matrixes. Graphene oxide can be obtained by using the dry ice method $\left(\mathrm{CO}_{2}\right.$ atmosphere $)$ [1] . This method produce magnesium chloride $\left(\mathrm{MgCl}_{2}\right)$ and hydrochloric acid $(\mathrm{HCl})$ as waste after obtaining the graphene oxide [2], which makes it more environment friendly compared to the Brodie method, Staudenmaier method and Hummers method, which require the use of oxidants such as concentrated sulfuric acid $\left(\mathrm{H}_{2} \mathrm{SO}_{4}\right)$, nitric acid $\left(\mathrm{HNO}_{3}\right)$ and potassium permanganate $\left(\mathrm{KM}_{\mathrm{n}} \mathrm{O}_{4}\right)$ which latter become toxic wastes. A classification of graphene-based materials can be performed. Initially, monolayer graphene is the one-atom-thick material in which $\mathrm{sp}^{2}$ bonded carbon atoms are hexagonally-arranged. Few-layer graphene is the material consisting of 2-5 sheets of graphene, while multi-layer graphene consists of 5-10 layers of graphene. Moreover, graphite nanoplatelets also consist of graphene sheets but their lateral dimensions/thickness are higher than those of many-layer graphene (more than 10 layers, less than $100 \mathrm{~nm}$ thickness) [3].

The multilayer graphene oxide was obtained by burning metallic $\mathrm{Mg}$ inside a $\mathrm{CO}_{2}$ atmosphere in a cavity of dry ice. The product of the chemical reaction is a powder mixture of unreacted metallic $\mathrm{Mg}$, $\mathrm{MgO}$ and graphene oxide which latter was cleaned in a 1:1 solution of $\mathrm{HCl}$ and deionized water and vacuum filtered to remove the $\mathrm{MgCl}_{2}$ produced doe the reaction of the $\mathrm{HCl}$ with the $\mathrm{MgO}$ and the metallic unreacted $\mathrm{Mg}$. The graphene oxide obtained was submitted to a thermic reduction process in a Thermolyne 21100 tube furnace at $850^{\circ} \mathrm{C}$ in a $200 \mathrm{~cm}^{3} / \mathrm{min}$ flow atmosphere of $95 / 5 \mathrm{Ar}-\mathrm{H}$ for $1 \mathrm{~h}$. GO and RGO powders were characterized by XRD using a Panalytical X'Pert PRO diffractometer and by TEM using a Hitachi TEM77000.

Fig. 1 shows the DRX patterns of graphene oxide and reduce graphene oxide, in which can be clearly seen the decrease of the graphene oxide reflection due to the reduction process mentioned before. Also, it can be seen a low intensity reflection of $\mathrm{MgO}$ which can be derivate from some residues in the cleaning process with $\mathrm{HCl}$. Transmission electron microscope (TEM) images of graphene oxide and reduce graphene oxide are shown in Fig. 2. Fig. 2a shows multi-layer graphene oxide with a 7 layers structure. In fig. $2 \mathrm{~b}$ it is noted a multi-layer reduce graphene oxide structure with an average thickness of $0.43 \mathrm{~nm}$.

The multilayer graphene oxide and reduced graphene oxide obtained by the dry ice method and thermal reduction have a potential application in composite materials as well as in other applications. Being environmentally friendly and having a low cost production process make this method a good alternative to fabricate graphene [4]. 


\section{References:}

[1] Juan Zhang, Chemical Physics Letters 591 (2014), p. 78.

[2] Amartya Chakrabarti, J. Mater. Chem. 21 (2011), p. 9491.

[3] Dimitrios G. Papageorgiou, Progress in Materials Science 90 (2017), p. 75.

[4] The authors acknowledge to the Red Temática Nacional de Aeronáutica, Red Materiales Compuestos and Red Temática de Nanociencias y Nanotecnología (152992).

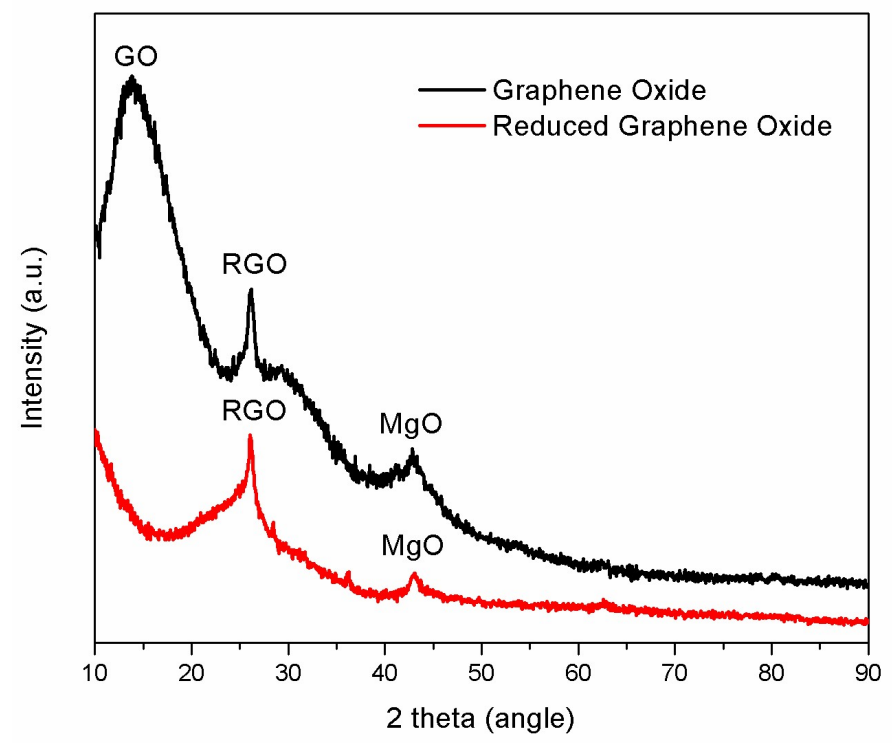

Figure 1. Diffraction pattern of graphene and graphene oxide.

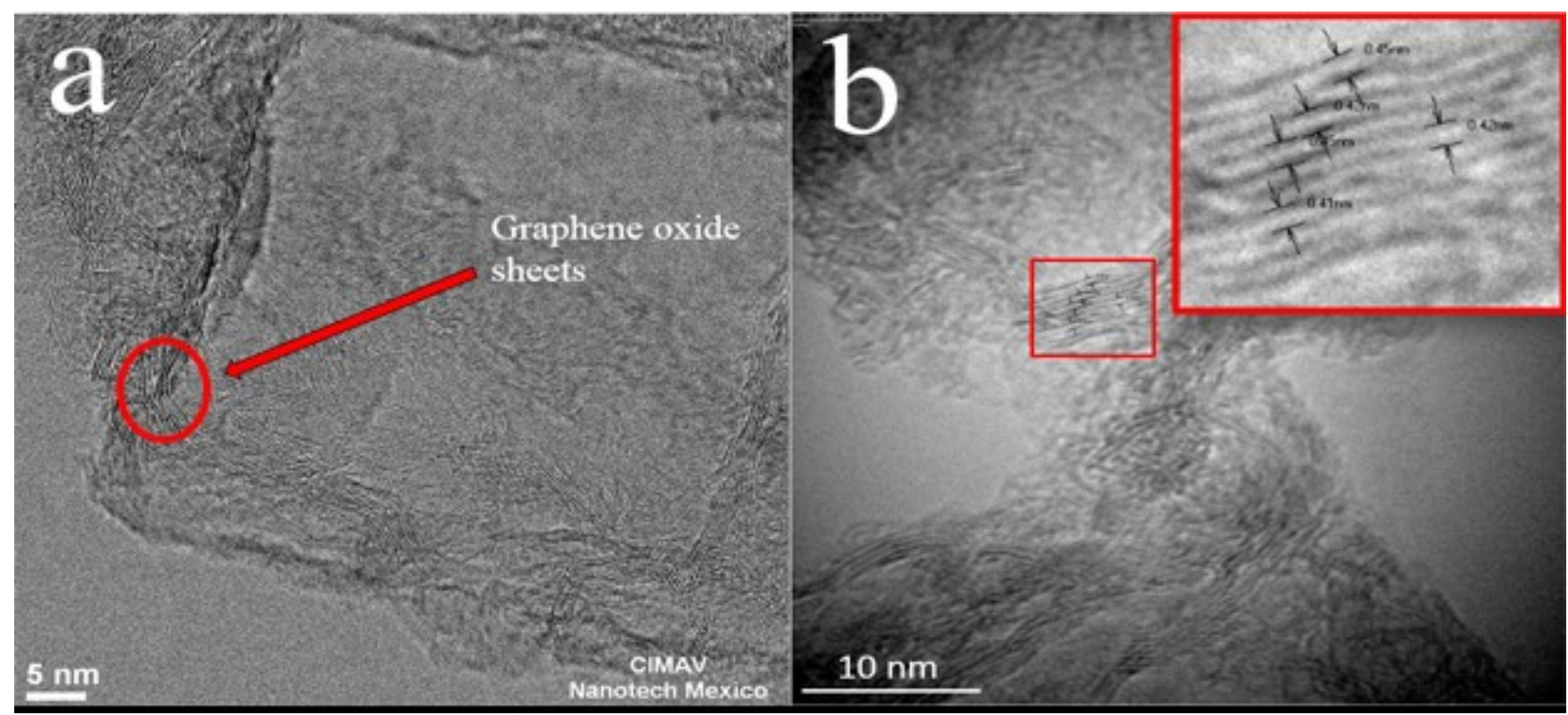

Figure 2. TEM image of graphene oxide (a), TEM image of graphene (b). 